\title{
Knowledge and practice of postoperative nausea, vomiting management, and predictors of knowledge among health professionals in referral hospitals of northwest Ethiopia, 2019
}

\author{
Tikuneh Yetneberk \\ Debre Tabor University \\ Yewlsew Fentie ( $\nabla$ fyewlsew@gmail.com ) \\ Debre Tabor University \\ Hailu Yimer \\ University of Gondar \\ Tadesse Belayneh \\ University of Gondar \\ Abraham Tarekegn \\ University of Gondar
}

\section{Research}

Keywords: Postoperative nausea and vomiting, knowledge, practice, health professionals

Posted Date: March 30th, 2020

DOI: https://doi.org/10.21203/rs.3.rs-18995/v1

License: () (i) This work is licensed under a Creative Commons Attribution 4.0 International License.

Read Full License 


\section{Abstract}

Background Good knowledge conjoined with evident practice of postoperative nausea, and vomiting management is vital for the optimal management of patients. On the other hand, inadequate knowledge and poor practice of health professionals on postoperative nausea vomiting risk reduction and management come up with complications, reduce patient satisfaction, increase patient, and hospital costs.

Objective To assess knowledge, practice, and predictors of knowledge regarding postoperative nausea and vomiting management among health professionals working in referral hospitals in northwest Ethiopia. Methods A multicenter cross-sectional study was conducted on 407 health professionals from February 27 to March 30, 2019, in referral hospitals in northwest Ethiopia. Stratified random $\llbracket$ Sampling followed by simple random sampling was used to select the study participants. Both bivariable and multivariable logistic regression were used to identify factors associated with the knowledge level of health professionals in PONV management. In the multivariable analysis, variables with a p-value $<0.05$ were considered statistically significant.

Results $52.8 \%$ of the study participants had good knowledge of PONV management (95\% Cl: 47.9-57.2). Male professionals were 1.95 times more likely knowledgeable as compared with females. The odds of physicians being knowledgeable were 5.36 times more likely than midwives, while the odds of anesthetists being knowledgeable were 3.88 times more likely than midwives. Professionals trained on PONV management were 5.32 (AOR: $5.32 ; 95 \% \mathrm{Cl}: 1.58,17.89)$ times more likely knowledgeable than those who did not train.

Conclusions Nearly fifty \% of healthcare providers working in the perioperative working areas had poor knowledge of PONV management. Gender, profession, and training on PONV management were factors significantly affecting the knowledge level of health professionals. Regular training seminars, continuous professional development, adherence to the latest guidelines, and conducting clinical audits are recommended to increase knowledge and improve the practices of health professionals in postoperative nausea vomiting management.

\section{Background}

Postoperative nausea and vomiting is a common undesirable side effect of surgery and anesthesia, which results in patients with simple to severe complications $(1,2)$. It also decreases patient and family satisfaction with overall healthcare (1). The incidence of PONV in adults reaches $25-30 \%$, and this incidence increases up to $60-80 \%$ in high-risk patients (3). A study done in Ethiopia showed that the incidence of PONV was $36.2 \%$ (2). Knowledge of health care professionals on PONV and antiemetic prescription practices causes PONV still undertreated(4). Poor knowledge about PONV management negatively affects the patient, but there are situations in which health professionals can't intervene PONV even if the factors causing nausea, and vomiting are identified by professionals (5). Knowledge and 
perception of health professionals regarding the consequences of PONV are limited, which leads them not to give attention to prevention strategies (6).

The practice pattern of most health professionals depends on pharmacological management without giving attention to non-pharmacological treatment approaches (7). Even though there was an advancement in anesthesia, anti-emetic drugs, and management strategies for PONV, the incidence is still high (8). To improve PONV management practice, health professionals should have good knowledge of it and need to properly implement treatment standards before and after PONV occurrence (11).

\section{Methods And Materials}

A multi-center cross-sectional study was conducted from February 27 to March 30, 2019, in referral hospitals in Northwest Ethiopia. The study was conducted at Debre Markos, Felege Hiwot, Tibebe Ghion, and University of Gondar Referral hospitals of northwest Ethiopia. All physicians, anesthetists, nurses, and midwives who were working in the operation room, recovery room, and surgical wards during the study period were recruited in the study. Stratified random sampling followed by a simple random sampling technique was employed to get the study participants. A total of 424 health professionals participated in the study. The total number of health care professionals was obtained from the human resource management (HRM) of each referral hospital. The study participants included in the study were proportionate depending on the number of professionals in each referral hospital.

The data were collected using a self-administered questionnaire, and the knowledge part of the questionnaire was taken from a previous study done in Canada with some modification to different professions with a reliability coefficient (Cronbach's alpha) of 0.78 (13). The practice questionnaire was taken from an evidence-based practice tool prepared by a multidisciplinary panel of experts on PONV management with some modifications (22).

The data were entered into Epidata version 4.2 and exported to SPSS version 20 for analysis. Descriptive statistics were carried out, and both bi-variable and multivariable logistic regression analyses were used to identify factors associated with the knowledge level of health professionals. Variables with a p-value of less than $<0.2$ in the bivariable logistic analysis were fitted into a multivariable logistic regression analysis. Both crude odds ratio (COR) in bivariable logistic regression and adjusted odds ratio (AOR) in multivariable logistic regression with the corresponding $95 \%$ confidence interval were calculated to show the strength of association. In multivariable logistic regression analysis, variables with a p-value $<0.05$ were considered statistically significant.

Ethical clearance was obtained from the UoG College of Medicine and Health Science, School of medicine ethical review committee. Written informed consent was obtained from each study participant.

\section{Operational definitions}


Good knowledge: When $60 \%$ or more knowledge questions are answered by respondents, who are expected to have the necessary knowledge about PONV and treat effectively $(12,13)$.

Poor knowledge: If less than $60 \%$ of knowledge questions are answered by respondents, they have poor knowledge about PONV and treat ineffectively $(12,13)$.

Postoperative nausea, and vomiting management: Includes components of PONV prevention/risk reduction and postoperative PONV intervention up to post-discharge time $(22,26)$.

\section{Results}

\section{Demographic and work-related characteristics of the study participants}

A total of 407 study participants were involved in this study, with a response rate of $96 \%$. There were seventeen incomplete questionnaires which were excluded from the data. The majority of health professionals were a Bachelor of Science degree (57\%) with less than five years of work experience (68.3\%). A large number of study participants worked in the recovery room and surgical wards (Table 1). 
Table 1

Socio-demographic characteristics of the study participants, northwest Ethiopia, 2019, ( $n=407)$.

\section{Variables}

Age in years

$<25$

$25-30$

$31-35$

36 and above

Sex

Male

Female

Profession

Physician

Anesthetist

Nurse

Midwife

Educational level

BSc degree

Master's degree

Resident

Specialist and above

Work experience (years)

$<5$

5-10

Above 10

Specific work area

Operation room only

Recovery room only

*Ward (general surgery ward, orthopedic surgical ward, gynecology ward, obstetrics surgical ward, ophthalmic wards).

\section{Frequency (n) Percentage (\%)}

83

20.4

222

54.5

75

18.4

27

6.6

272

66.8

135

33.2

151

37.1

43

10.6

118

29

95

23.3

232

57.0

80

19.7

72

17.7

23

5.7

278

68.3

92

22.6

37

9.1

30

7.4

69

17.0 


\begin{tabular}{|lll|}
\hline Variables & Frequency (n) & Percentage (\%) \\
\hline ward* & 193 & 47.4 \\
\hline Operation room and recovery room & 115 & 28.3 \\
\hline Learn the PONV management course in an academic class. & & \\
\hline Yes & 353 & 86.7 \\
\hline No & 54 & 13.3 \\
\hline Take training on PONV management & & \\
\hline Yes & 21 & 5.2 \\
\hline No & 386 & 94.8 \\
\hline $\begin{array}{l}\text { *Ward (general surgery ward, orthopedic surgical ward, gynecology ward, obstetrics surgical ward, } \\
\text { ophthalmic wards). }\end{array}$ & \\
\hline
\end{tabular}

\section{Knowledge of the study participants regarding PONV management}

$52.8 \%$ of the study participants had good knowledge of PONV management. Physicians (70.9\%) and anesthetists (69.8\%) were equivalently answered greater than $60 \%$ of the knowledge questions (Fig. 2).

The mean percentage score of correctly answered questions from the aggregate score was $59.6 \%$.

"Women are more likely to suffer from PONV than men and metoclopramide can cause drowsiness", were the most answered questions, whereas "the majority of patients are more worried about pain than PONV" was the least answered question (Table 2). 
Table 2

knowledge questions answered correctly by health professionals working in referral hospitals of northwest Ethiopia, 2019, $(n=407)$.

\section{Knowledge questions}

The overall incidence of PONV is less than ten percent $(F)$

Women are more likely to suffer from PONV than men $(T)$

The majority of patients are more worried about pain than PONV $(\mathrm{F})$

PONV is unpleasant, but, rarely causes a delay in recovery time after surgery $(F)$

There is a strong relationship between motion sickness and PONV (T)

Prolonged pre-operative fasting can result in PONV $(T)$

Use of inhalational anesthetic agents by anesthetists help to reduce the incidence of PONV (F)

Opioids can affect PONV because they increase gastric motility (F)

When transporting back to the ward from recovery room supine position is best for preventing PONV (F)

If there is no evidence of abdominal distention, sips of fluid can usually be recommended two hours after surgery $(T)$

Surgery greater than 30 minutes increase the risk of PONV (T)

Regional anesthesia increases the risk of PONV (F)

Gynecological surgeries are high-risk procedures for PONV $(T)$

Pediatrics patients age $<3$ years are at higher risk for PONV than older children.

Cimetidine is a dopaminergic antagonist anti-emetic drug (F)

Hypertension is more likely to cause PONV than hypotension $(F)$

Nausea is a normal reaction to surgery and does not need any intervention unless it results in vomiting $(F)$

Adequate IV fluid hydration is an effective strategy for reducing the baseline risk for PONV (T)

Smokers are less likely to experience PONV (T)

PONV is more common following orthopedic surgery $(F)$
Frequency

(n)

240

341

94

124

283

262

169

169

41.5

241

52.6

205

50.4

303

74.4

198

48.6

281

69

174

42.8

266

65.4

227

55.8

223

54.8

330

81.1

205

50.4

204

50.1

The correct answer to the questions: $\mathrm{F}=$ false, $\mathrm{T}=$ true 


\begin{tabular}{|lll|}
\hline Knowledge questions & $\begin{array}{l}\text { Frequency } \\
\text { (n) }\end{array}$ & $\begin{array}{l}\text { Percentage } \\
\text { (\%) }\end{array}$ \\
\hline TIVA with ketamine is preferred for prevention of PONV (F) & 167 & 41.0 \\
\hline $\begin{array}{l}\text { Dexamethasone is considered an effective anti-emetic, especially after } \\
\text { laparoscopic surgery (T) }\end{array}$ & 322 & 79.1 \\
\hline Metoclopramide can cause drowsiness (T) & 341 & 83.8 \\
\hline Acupuncture is a none pharmacological prophylaxis for PONV (T). & 327 & 80. \\
\hline Promethazine can be administered in any IV site (F) & 250 & 61.4 \\
\hline The correct answer to the questions: $\mathrm{F}=$ false, $\mathrm{T}=$ true & & \\
\hline
\end{tabular}

\section{Practice of the study participants on PONV management}

This study showed that $7.9 \%$ of health professionals had guidelines in their workplace and $18.7 \%$ of professionals responded that they had given antiemetic's based on guidelines. $71.9 \%$ of the anesthetists had guidelines in their workplace, and $38.2 \%$ gave antiemetics based on guidelines (Fig. 3).

$28.5 \%$ of the study participants were provided antiemetic prophylaxis while $95.6 \%$ were managing postoperative nausea vomiting after surgery. Provision of antiemetic prophylaxis based on risk stratification and without risk stratification was done by a small number of respondents as compared to that didn't give antiemetic prophylaxis (Table 3 ). 
Table 3

the practice of health professionals in PONV management working in referral hospitals of northwest Ethiopia, 2019, $(n=407)$.

\section{Practice questions}

\section{Profession}

\begin{tabular}{|c|c|c|}
\hline $\begin{array}{l}\text { Physician } \\
\mathrm{n}(\%)\end{array}$ & $\begin{array}{l}\text { Anesthetist } \\
\mathrm{n}(\%)\end{array}$ & $\begin{array}{l}\text { Nurse } \\
\mathrm{n}(\%)\end{array}$ \\
\hline
\end{tabular}

Responsible to administer antiemetic prophylaxis

\begin{tabular}{lllll} 
Yes & $69(45.7 \%)$ & $39(90.7 \%)$ & $6(5.1 \%)$ & $2(2.1 \%)$ \\
\hline No & $82(54.3 \%)$ & $4(9.3 \%)$ & $112(94.9 \%)$ & $93(97.9 \%)$
\end{tabular}

Stratify patients based on risk factors

$\begin{array}{lllll}\text { Yes } & 27(17.9 \%) & 26(60.5 \%) & 14(11.9 \%) & 11(12.0 \%) \\ \text { No } & 124(82.1 \%) & 17(39.5 \%) & 104(88.1 \%) & 81(88.0 \%)\end{array}$

Give antiemetic's based on risk factors

\begin{tabular}{lllll} 
Yes & $15(9.9 \%)$ & $26(60.5 \%)$ & $4(3.4 \%)$ & $1(1.1 \%)$ \\
\hline No & $136(90.1 \%)$ & $17(39.5 \%)$ & $114(96.6 \%)$ & $94(98.9 \%)$
\end{tabular}

Anti-emetic prophylaxis for low-risk patients

\begin{tabular}{|lllll|}
\hline No anti-emetic & $3(18.8 \%)$ & $6(23.1 \%)$ & $0(0.0 \%)$ & $0(0.0 \%)$ \\
\hline Single anti-emetic & $11(68.8 \%)$ & $18(69.2 \%)$ & $4(100.0 \%)$ & $2(100.0 \%)$ \\
\hline Two anti-emetics & $2(12.5 \%)$ & $2(7.7 \%)$ & $0(0.0 \%)$ & $0(0.0 \%)$ \\
\hline More than two antiemetic & $0(0.0 \%)$ & $0(0.0 \%)$ & $0(0,0 \%)$ & $0(0.0 \%)$ \\
\hline $\begin{array}{l}\text { Anti-emetic prophylaxis for moderate- } \\
\text { risk patients }\end{array}$ & & & & \\
\hline No anti-emetic & $1(6.7 \%)$ & $0(0.0 \%)$ & $0(0.0 \%)$ & $0(0.0 \%)$ \\
\hline Single anti-emetic & $1(6.7 \%)$ & $6(23.1 \%)$ & $1(25.0 \%)$ & $0(0.0 \%)$ \\
\hline $\begin{array}{l}\text { Two anti-emetics } \\
\text { More than two antiemetic }\end{array}$ & $13(86.7 \%)$ & $17(65.4 \%)$ & $3(75.0 \%)$ & $1(100.0 \%)$ \\
\hline $\begin{array}{l}\text { Anti-emetic prophylaxis for high-risk } \\
\text { patients }\end{array}$ & $0(0.0 \%)$ & $3(11.5 \%)$ & $0(0.0 \%)$ & $0(0.0 \%)$ \\
\hline No anti-emetic & $0(0.0 \%)$ & $1(3.8 \%)$ & $0(0.0 \% 0$ & $0(0.0 \%)$ \\
\hline $\begin{array}{l}\text { Single anti-emetic } \\
\text { n }\end{array}$ & $0(0.0 \%)$ & $0(0.0 \%)$ & $1(25.0 \%)$ & $0(0.0 \%)$ \\
\hline
\end{tabular}




\section{Practice questions}

Two anti-emetics

More than two antiemetic

Give anti-emetic prophylaxis without risk stratification

Yes

No

Give anti-emetics as a multimodal approach

Yes

No

Responsible to manage nausea \&vomiting postoperatively at recovery/surgical ward

Yes

No

Give antiemetic at recovery room or surgical wards

Yes

No

Apply multimodal drug management if nausea and vomiting occur postoperatively

Yes

No

Apply a non-pharmacological treatment approach

\section{Profession}

\begin{tabular}{llll}
$6(40.0 \%)$ & $8(30.8 \%)$ & $1(25.0 \%)$ & $0(0.0 \%)$ \\
\hline $9(60.0 \%)$ & $17(65.4 \%)$ & $2(50.0 \%)$ & $1(100.0 \%)$
\end{tabular}

\begin{tabular}{llll}
\hline $55(36.4 \%)$ & $13(30.2 \%)$ & $2(1.7 \%)$ & $0(0.0 \%)$ \\
\hline $96(63.6 \%)$ & $30(69.8 \%)$ & $116(98.3 \%)$ & $95(100.0 \%)$
\end{tabular}

\begin{tabular}{llll}
$35(63.6 \%)$ & $12(85.7 \%)$ & $1(50.0 \%)$ & $0(0.0 \%)$ \\
\hline $20(36.4 \%)$ & $2(14.3 \%)$ & $1(50.0 \%)$ & $0(0.0 \%)$
\end{tabular}

\begin{tabular}{llll}
$149(98.7 \%)$ & $28(65.1 \%)$ & $117(99.2 \%)$ & $95(100 \%)$ \\
\hline $2(1.3 \%)$ & $15(34.9 \%)$ & $1(0.8 \%)$ & $0(0.0 \%)$
\end{tabular}

\begin{tabular}{lllll} 
Yes & $151(100.0 \%)$ & $42(97.7 \%)$ & $118(100.0 \%)$ & $93(97.9 \%)$ \\
No & $0(0.0 \%)$ & $1(2.3 \%)$ & $0(0.0 \%)$ & $2(2.1 \%)$ \\
\hline
\end{tabular}

\section{Factors associated with knowledge of health professionals regarding PONV management}


The multivariable logistic regression analysis showed that male professionals were 1.95 (AOR: 1.95; $95 \% \mathrm{Cl}: 1.20,3.17)$ times more likely knowledgeable as compared with females. The odds of physicians being knowledgeable were 5.36 (AOR: 5.36 ; $95 \% \mathrm{Cl}: 2.20,13.05)$ times more likely than midwives, and the odds of anesthetists being knowledgeable were 3.88 (AOR: $3.88 ; 95 \% \mathrm{Cl}: 1.66,9.08$ ) times more likely than midwives. Professionals who took training on PONV management were 5.32 (AOR: 5.32; 95\%Cl: 1.58, 17.89) times more likely knowledgeable than professionals who did not take training (Table 4). 
Table 4

Factors affecting the knowledge level of health professionals working in referral hospitals in northwest Ethiopia $(n=407)$.

\begin{tabular}{|c|c|c|c|c|c|}
\hline \multirow[t]{2}{*}{ Variables } & \multicolumn{2}{|c|}{ Knowledge level } & \multirow{2}{*}{$\begin{array}{l}\text { Crude odds ratio } \\
(95 \% \mathrm{Cl})\end{array}$} & \multirow{2}{*}{$\begin{array}{l}\begin{array}{l}\text { Adjusted } \\
\text { odds ratio }\end{array} \\
(95 \% \mathrm{Cl})\end{array}$} & \multirow{2}{*}{$\begin{array}{l}\text { p- } \\
\text { value }\end{array}$} \\
\hline & $\begin{array}{l}\text { Good } \\
215 \\
(52.8 \%)\end{array}$ & $\begin{array}{l}\text { Poor } \\
\text { 192(47.2\%) }\end{array}$ & & & \\
\hline \multicolumn{6}{|l|}{ Sex } \\
\hline Male & $166(77.2 \%)$ & $106(55.2 \%)$ & $2.75(1.79,4.21)$ & $\begin{array}{l}1.95(1.20, \\
3.17)\end{array}$ & $0.007 *$ \\
\hline Female & $49(22.8 \%)$ & $86(44.8 \%)$ & 1 & & \\
\hline \multicolumn{6}{|l|}{ Profession } \\
\hline Physician & $107(49.8 \%)$ & $44(22.9 \%)$ & $0.07(0.02,0.30)$ & $\begin{array}{l}5.36(2.20 \\
13.05)\end{array}$ & $0.00 *$ \\
\hline Anesthetist & $30(14.0 \%)$ & $13(6.8 \%)$ & $0.19(0.04,0.86)$ & $\begin{array}{l}3.88(1.66 \\
9.08)\end{array}$ & $0.002^{*}$ \\
\hline Nurse & $44(20.5 \%)$ & 74(38.5\%) & $0.15(0.03,0.69)$ & $\begin{array}{l}1.06(0.58 \\
1.94)\end{array}$ & 0.85 \\
\hline Midwife & $34(15.7 \%)$ & 61(31.8\%) & 1 & & \\
\hline \multicolumn{6}{|l|}{ Level of education } \\
\hline BSc degree & $97(45.1 \%)$ & $135(70.3 \%)$ & 1 & & \\
\hline Master's degree & $53(24.7 \%)$ & $27(14.1 \%)$ & $2.73(1.61,4.65)$ & $\begin{array}{l}0.87(0.41 \\
1.82)\end{array}$ & 0.71 \\
\hline Resident & $44(20.5 \%)$ & $28(14.6 \%)$ & $2.19(1.27,3.76)$ & $\begin{array}{l}0.50(0.20 \\
1.26)\end{array}$ & 0.14 \\
\hline Specialist and above & $21(9.8 \%)$ & $2(1.0 \%)$ & $14.61(3.35,63.80)$ & $\begin{array}{l}3.10(0.59 \\
16.27)\end{array}$ & 0.18 \\
\hline \multicolumn{6}{|l|}{$\begin{array}{l}\text { learned PONV in } \\
\text { academic classes }\end{array}$} \\
\hline Yes & 194(90.2\%) & 159(82.8\%) & $1.92(1.07,3.45)$ & $\begin{array}{l}0.86(0.45 \\
1.66)\end{array}$ & 0.65 \\
\hline No & $21(9.8 \%)$ & $33(17.2 \%)$ & 1 & & \\
\hline
\end{tabular}

* $=$ p-value $<0.051=$ reference 


\begin{tabular}{|lccccc|}
\hline Variables & Knowledge level & Crude odds ratio & $\begin{array}{l}\text { Adjusted } \\
\text { odds ratio }\end{array}$ & $\begin{array}{l}\text { p- } \\
\text { value }\end{array}$ \\
\hline Yes & $17(7.9 \%)$ & $4(2.1 \%)$ & $4.04(1.33,12.21)$ & $\begin{array}{l}5.32(1.58, \\
17.89)\end{array}$ & $0.007^{*}$ \\
\hline No & $198(92.1 \%)$ & $188(97.9 \%)$ & 1 & \\
\hline$*=$ p-value $<0.051$ reference & & & \\
\hline
\end{tabular}

\section{Discussion}

Knowledge and evident practice of health professionals on PONV risk reduction and management approaches have a great role in the reduction of PONV following anesthesia and surgery. This study showed that the knowledge level of health professionals on PONV was $52.8 \%$ (95\% Cl: 47.9-57.2). This result was relatively similar to a study done in Singapore on which $50.6 \%$ of the respondents had good knowledge of PONV management in pediatric patients (4). The mean percentage score of correctly answered questions from the aggregate score was $59.6 \%$, which was similar to a study done in Canada with a mean percentage score of $61.34 \%$ (13). The likely reason might be due to the similarity of some knowledge questions of PONV management.

Gender was associated with knowledge of PONV in this study, and males were more likely to answer knowledge questions about PONV than females with AOR: $1.72(1.06,2.81)$. This result was different from a study done in Chicago, on the knowledge of certified registered nurse anesthetists in which females had a higher knowledge level than males (mean score of $45.82 \mathrm{vs.} \mathrm{43.21)} \mathrm{(14).} \mathrm{This} \mathrm{might} \mathrm{be}$ due to the variation in knowledge questions or variation in the profession and extent of education, since this study included a variety of professions with different levels of education.

Type of profession was another factor that was associated with knowledge of PONV management, and the odds of physicians being knowledgeable were 5.36 (AOR: $5.36 ; 95 \% \mathrm{Cl}: 2.20,13.05$ ) times more likely than midwives, while the odds of anesthetists being knowledgeable was 3.88 (AOR: 3.88; 95\%Cl: 1.66, 9.08) times more likely than midwives. This variation may be due to the experience of PONV management or interprofessional variation in the scope of training on PONV management (27). Health professionals who took training for PONV were associated with the knowledge level of PONV management in which the odds of health professionals who took training were 5.32(AOR: $5.32 ; 95 \% \mathrm{Cl}$ : $1.58,17.89)$ times more likely knowledgeable than those who did not take the training. This might show that training might improve the knowledge level of health professionals in PONV management (28).

Prevention of PONV by giving prophylactic antiemetic drugs and early management when PONV occurs is vital in the reduction of PONV (7). However, due to a lack of standard protocols for the prevention and management of PONV, variations in the availability of antiemetic drugs, and other factors lead to variations in the practice of PONV prevention and management (23). In this study majority of antiemetic prophylaxis was provided by anesthetists $90.7 \%$; $p<0.001$ as compared with physicians $45.7 \% ; p<0.001$, 
nurses $5.1 \% ; p=0.001$ and midwives $2.1 \% ; p<0.001$ ). This was higher than that in a study done in Switzerland among surgeons and anesthesiologists in which they were found that anesthesiologists practice antiemetic prophylaxis than surgeons $(77 \%$ vs. $45 \%$; $p<0.01)(11)$. This discrepancy may be due to differences in the task handling the responsibility of professionals, differences in educational level, and variation in the number of professionals involved in the study.

In this study, all professionals equivalently responded to the application of non-pharmacological management of PONV, physicians $100.0 \%$, anesthetist $97.7 \%$, nurse $100.0 \%$, and $97.9 \%$ of midwives. This result is similar to the study done in the USA in which fluid administration and nasal oxygen were the most commonly applied non-pharmacologic management (7). The limitation of this study was the use of a knowledge assessment tool validated in the nursing profession for all health professionals, and there may be recall bias in practice assessment tools due to individual differences in responding practice questions. The other weakness of this study may be that some factors associated with knowledge of PONV management were not discussed in other studies due to the limited number of studies on this topic.

\section{Conclusion}

Nearly fifty \% of healthcare providers working in perioperative working areas had poor knowledge of PONV management. Gender, profession, and training on PONV management were factors significantly affecting the knowledge level of health professionals. Anesthetists were more working on antiemetic prophylaxis provision and the majority of PONV management following surgery was done by nurses, midwives, and physicians.

\section{Abbreviations}

AOR Adjusted Odds Ratio

COR Crude Odds Ratio

HRM Human Resource Management

PONV Post-Operative Nausea Vomiting

UoG University of Gondar

USA United States of America

\section{Declarations}

\section{Ethical approval and consent to participate}


To keep the ethical soundness of the research, an ethical approval letter was obtained from the Institutional Review Board (IRB) of the University of Gondar College of Medicine and Health Sciences. Written consent was also secured before data collection.

\section{Consent for publication}

Not applicable.

\section{Availability of data and materials}

All data generated or analyzed during this study are included in this article

\section{Funding}

The entire funding to conduct this study was provided by the University of Gondar College of Medicine and Health Science, Gondar, Ethiopia.

\section{Competing interests}

The authors declare that they have no competing interests.

\section{Contributions}

YF initiated the idea, carried out the study, and involved in drafting the manuscript. TY contributed to the statistical analysis and preparation of the manuscript. TB and HY contributed to the entry, analysis, critically revised the paper and provided the final version. AT and YF edit starting from the proposal development up to the final manuscript writing and critically reviewed the manuscript for intellectual content. All authors have read and approved the final manuscript.

\section{Acknowledgment}

We would like to give our thank the University of Gondar College of Medicine and Health Science for funding the research project and our heartfelt gratitude also extends to data collectors and respected study participants.

\section{References}

1. Dienemann J, Hudgens AN, Martin D, Jones $H$, Hunt R, Blackwell R, et al. Risk factors of patients with and without postoperative nausea (PON). Journal of PeriAnesthesia Nursing. 2012;27(4):252-8.

2. Endale G/Egziabher G/medhn JH, Danielle Reddi , Tadesse Belayneh Melkie. Prevalence and Factors Associated with Post Operative Nausea and Vomiting at the University of Gondar Teaching Hospital, Northwest Ethiopia. Ethiop J Health Biomed Sci. 2014;6(1):1-9.

3. White PF, O'hara JF, Roberson CR, Wender RH, Candiotti KA. The impact of current antiemetic practices on patient outcomes: a prospective study on high-risk patients. Anesthesia \& Analgesia. 
2008;107(2):452-8.

4. Jiaming L, Mai JLJ. PONV Attitudes, Knowledge and Antiemiemetic Prescribing Practices Among Surgeons in a Paediatrics Hospital Macrojornals. 2015;3(1):1-25.

5. Sussanne B, Arweström C, Baker A, Berterö C. Nurses' experiences in the relief of postoperative nausea and vomiting. Journal of clinical nursing. 2010;19(13-14):1865-72.

6. Kappen TH, Van Loon K, Kappen MA, Van Wolfswinkel L, Vergouwe Y, Van Klei WA, et al. Barriers and facilitators perceived by physicians when using prediction models in practice. Journal of clinical epidemiology. 2016;70:136-45.

7. Macario A, Claybon L, Pergolizzi JV. Anesthesiologists' practice patterns for treatment of postoperative nausea and vomiting in the ambulatory Post Anesthesia Care Unit. BMC anesthesiology. 2006;6(1):1-6.

8. Biedler A, Wermelt J, Kunitz O, Müller A, Wilhelm W, Dethling J, et al. A risk-adapted approach reduces the overall institutional incidence of postoperative nausea and vomiting. Canadian Journal of Anesthesia. 2004;51(1):13-9.

9. Smith CA, Haas RE. Sustaining reductions in postoperative nausea and vomiting after evidencebased practice initiative: A success story. Journal of Health and Social Sciences. 2017;2(2):149-60.

10. Eberhart LH, Morin AM. Risk scores for predicting postoperative nausea and vomiting are clinically useful tools and should be used in every patient: Con-'life is simple, but we insist on making it complicated'. European Journal of Anaesthesiology (EJA). 2011;28(3):155-9.

11. Wilder-Smith $\mathrm{OH}$, Martin NC, Morabia A. Postoperative nausea and vomiting: a comparative survey of the attitudes, perceptions, and practice of Swiss anesthesiologists and surgeons. Anesthesia \& Analgesia. 1997;84(4):826-31.

12. Jolley S. Post-operative nausea and vomiting: a survey of nurses' knowledge. Nursing Standard (through 2013). 2000;14(23):32.

13. Lewthwaite BJ. What do nurses know about post-operative nausea and vomiting? MedSurg Nursing. 2009;18(2):110-5.

14. Kuhn J, Homa K. Certified Registered Nurse Anesthetists (CRNA's) Knowledge and Attitudes Regarding Acupressure as an Adjunct to Postoperative Nausea and Vomiting Prevention. 2017;115(1):31-7.

15. Sigaut S, Merckx P, Peuch C, Necib S, Pingeon F, Mantz J. Does an educational strategy based on a systematic preoperative assessment of simplified Apfel's score decrease postoperative nausea and vomiting? ELSEVIER. 2010;29(11):765-9.

16. Myklejord DJ, Yao L, Liang H, Glurich I. Consensus guideline adoption for managing postoperative nausea and vomiting. WMJ. 2012;111(5):207-13.

17. DeLeskey K. The implementation of evidence-based practice for the prevention/management of post-operative nausea and vomiting. International Journal of Evidence-Based Healthcare. 2009;7(2):140-4. 
18. Kranke P, Eberhart L, Gan T, Roewer N, Tramèr M. Algorithms for the prevention of postoperative nausea and vomiting: an efficacy and efficiency simulation. European journal of anaesthesiology. 2007;24(10):856-67.

19. Habib AS, White WD, Eubanks S, Pappas TN, Gan TJ. A randomized comparison of a multimodal management strategy versus combination antiemetics for the prevention of postoperative nausea and vomiting. Anesthesia \& Analgesia. 2004;99(1):77-81.

20. Rüsch D, Eberhart LH, Wallenborn J, Kranke P. Nausea and vomiting after surgery under general anesthesia: an evidence-based review concerning risk assessment, prevention, and treatment. Deutsches Ärzteblatt International. 2010;107(42):733.

21. Pierre S, Corno G, Benais H, Apfel CC. A risk score-dependent antiemetic approach effectively reduces postoperative nausea and vomiting-a continuous quality improvement initiative. Canadian Journal of Anesthesia. 2004;51(4):320.

22. Gan TJ, Diemunsch P, Habib AS, Kovac A, Kranke P, Meyer TA, et al. Consensus guidelines for the management of postoperative nausea and vomiting. Anesthesia \& Analgesia. 2014;118(1):85-113.

23. Macario A, Chung A, Weinger MB. Variation in practice patterns of anesthesiologists in California for prophylaxis of postoperative nausea and vomiting6. Journal of clinical anesthesia. 2001;13(5):35360.

24. Dzwonczyk R, Weaver TE, Puente EG, Bergese SD. Postoperative nausea and vomiting prophylaxis from an economic point of view. American journal of therapeutics. 2012;19(1):11-5.

25. Murphy MJ, Hooper VD, Sullivan E, Clifford T, Apfel CC. Identification of risk factors for postoperative nausea and vomiting in the perianesthesia adult patient. Journal of perianesthesia nursing. 2006;21(6):377-84.

26. Gan TJ, Meyer T, Apfel CC, Chung F, Davis PJ, Eubanks S, et al. Consensus guidelines for managing postoperative nausea and vomiting. Anesthesia \& Analgesia. 2003;97(1):62-71.

27. Upton D, Upton P. Knowledge and use of evidence-based practice by allied health and health science professionals in the United Kingdom. Journal of allied health. 2006;35(3):127-33.

28. Steensma H, Groeneveld K. Evaluating a training using the "four levels model". Journal of Workplace Learning. 2010;22(5):319-31.

\section{Figures}




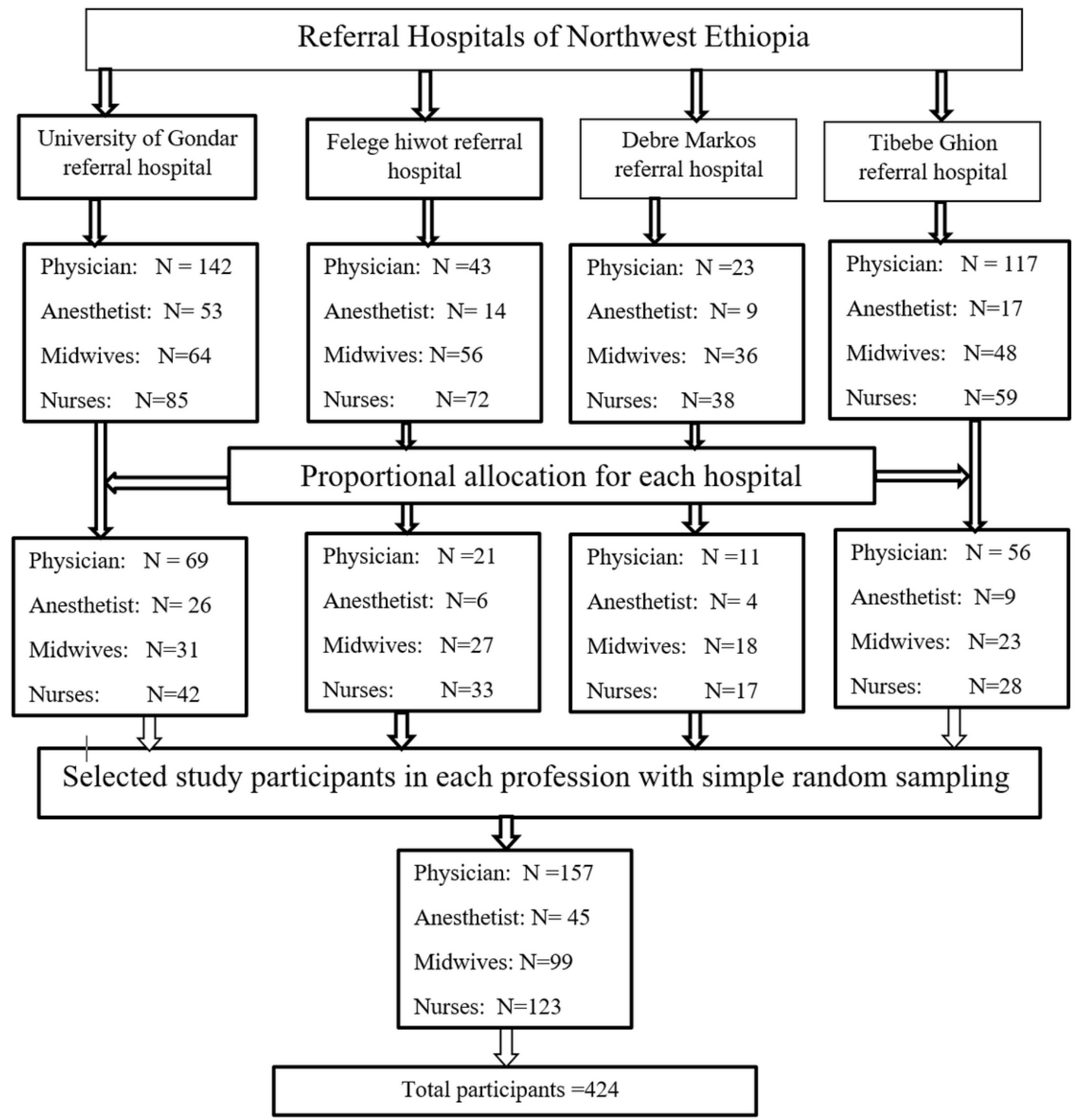

Figure 1

Schematic presentation of the sampling procedure. 


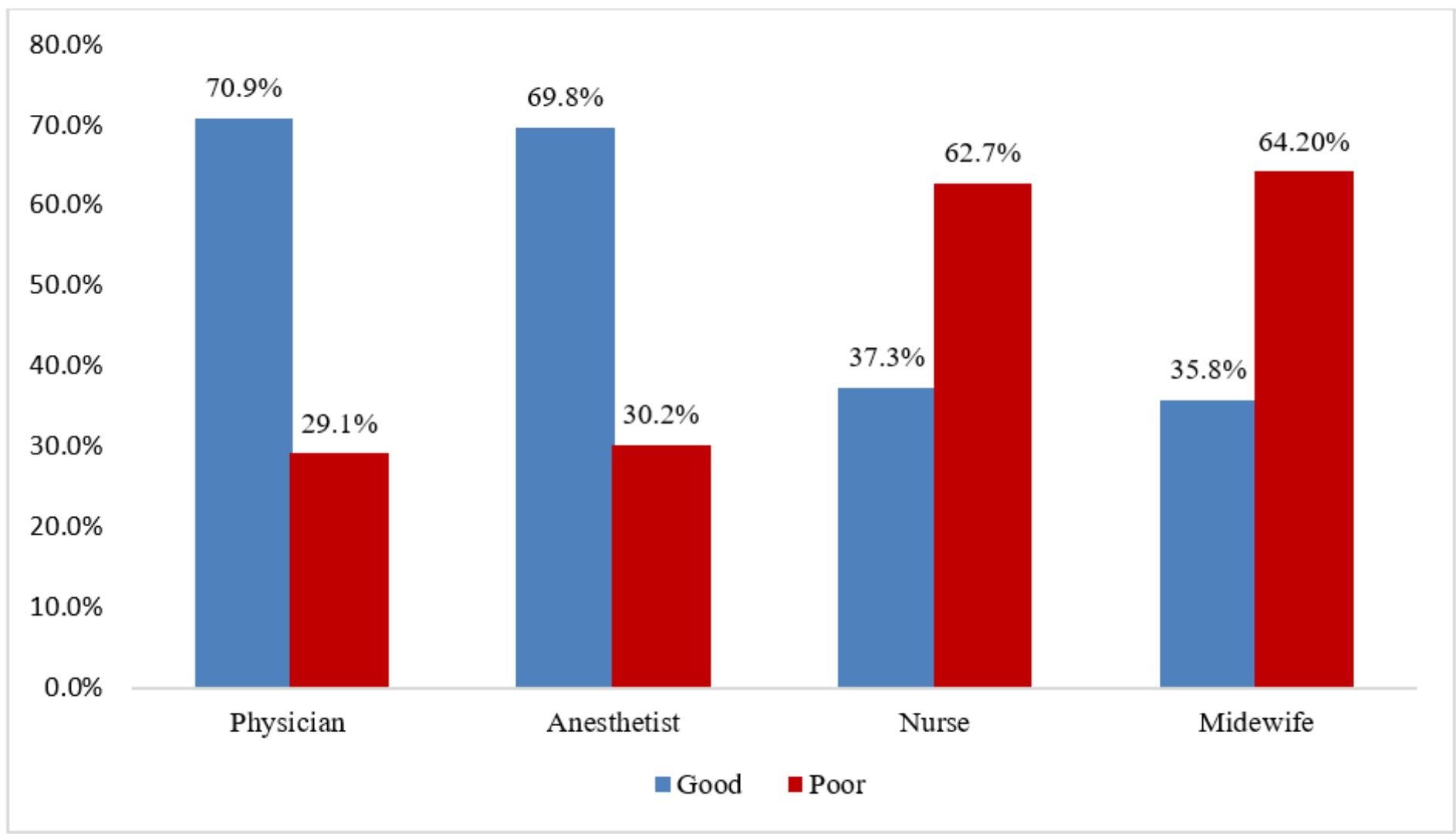

Figure 2

Knowledge level of health professional based on the field of study in referral hospitals of northwest Ethiopia, $2019(\mathrm{n}=407)$. 


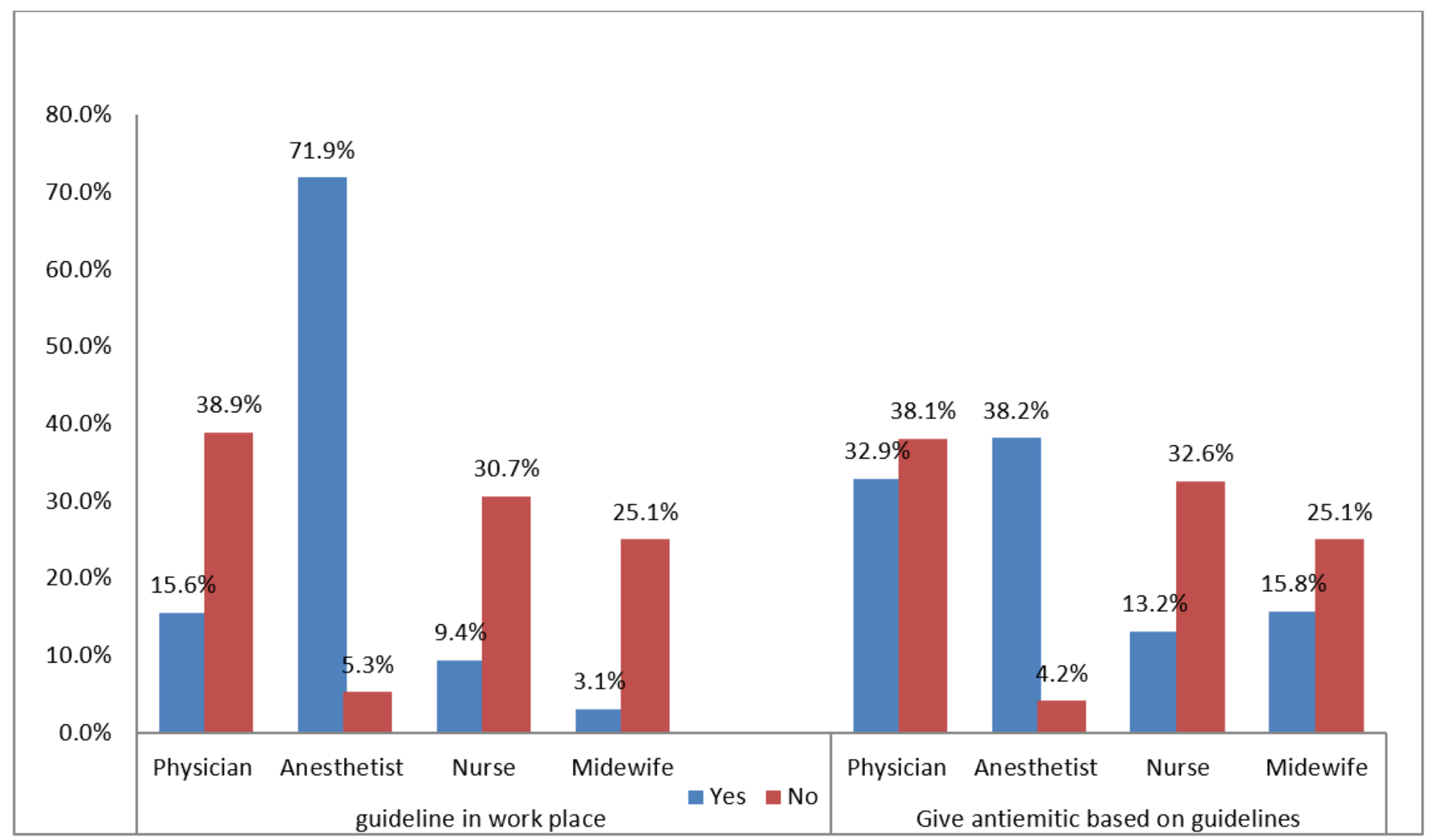

\section{Figure 3}

Health professionals who have guidelines in their workplace and give antiemetic based on the guideline recommendations. 